\title{
Bioactive compounds of juices from two Brazilian grape cultivars
}

\author{
Juliana Kelly da Silva, ${ }^{a}$ Cinthia Baú Betim Cazarin, ${ }^{a}$ Luiz Claudio Correa, ${ }^{b}$ \\ Ângela Giovana Batista, ${ }^{a}$ Cibele Priscila Busch Furlan, ${ }^{a}$ Aline Camarão Telles \\ Biasoto, ${ }^{\mathrm{b}}$ Giuliano Elias Pereira, ${ }^{\mathrm{c}}$ Adriano Costa de Camargo ${ }^{\mathrm{d}}$ and Mário \\ Roberto Maróstica Junior ${ }^{a^{*}}$
}

\begin{abstract}
BACKGROUND: Grape juice consumption may prevent several chronic diseases owing to the presence of phenolic compounds, which have an important role in the reduction of oxidative stress. This study investigated the polyphenol content and antioxidant activities of grape juices from two cultivars: BRS-Cora and Isabella. Total polyphenol content (TPC), anthocyanins, antioxidant capacity (oxygen radical absorbance capacity, ferric reducing antioxidant power and 1,1-diphenyl-2-picrylhydrazyl), and phenolic profile (high-performance liquid chromatography with diode array and fluorescence detection - HPLC-DAD-FLD) were determined.

RESULTS: BRS-Cora grape juice showed higher concentrations of total polyphenols and anthocyanins, as well as higher antioxidant potential, than those of Isabella grape juice. A significant positive correlation was found in TPC or anthocyanin contents when correlated with the remaining antioxidant assays. In addition, HPLC-DAD-FLD showed a higher total phenolic content in BRS-Cora grape juice compared to Isabella.
\end{abstract}

CONCLUSION: The present results show BRS-Cora as a promising cultivar for grape juice production with an improved functional potential.

(C) 2015 Society of Chemical Industry

Keywords: Isabella grape; BRS-Cora grape; grape juice; polyphenols; antioxidant potential; bioactive compounds

\section{INTRODUCTION}

Grapes, grape juice and wine have shown both in vitro and in vivo potential to prevent several chronic diseases. The benefits stem from their high polyphenol content, which are secondary metabolites produced by plants as a defense mechanism against environmental stress. $^{1-4}$ The protective effects against health problems such as cancer and cardiovascular diseases may be attributed to their antioxidant activity and antiproliferative properties. ${ }^{5}$ Furthermore, interest in polyphenols has increased owing to their potential activity as antitoxic and cytoprotective molecules with a modulatory action in inflammatory processes and neurodegenerative diseases. ${ }^{1-3,6,7}$

The search for natural sources of bioactive compounds is a strong trend nowadays. At the same time, an increase in the consumption of grapes and their products was noted, focusing not only on nutrition but also on their beneficial health effects. Grapes are sources of polyphenols belonging to different subclasses such as monomeric flavan-3-ols, proanthocyanidins, flavonoids, anthocyanins, phenolic acids and the stilbene resveratrol. ${ }^{8-11}$

Several factors such as geographic origin, cultivar and environmental conditions may influence polyphenol concentration. ${ }^{9,12-15}$ Different agronomic strategies have been employed to develop new crops, focusing on sensory quality, field production yield and resistance to pests and diseases, ${ }^{16,17}$ which, in turn, may influence the biosynthesis of phenolic compounds. ${ }^{12}$

Red wine is the most famous grape product, which has been correlated with the 'French paradox', in which low coronary disease death rates have been observed in France, despite the high amount of dietary cholesterol and saturated fatty acids. However, several studies have also reported improvements on health aspects with grape juice intake. Supplementation with Concord grape juice $\left(8 \mathrm{~mL} \mathrm{~kg}^{-1}\right.$ body weight $\left.\mathrm{d}^{-1}\right)$ for 14 days positively altered the endothelial function in adults with coronary artery

\footnotetext{
* Correspondence to: Mário Roberto Maróstica Junior, Departamento de Alimentos e Nutrição, Rua Monteiro Lobato 80, Cidade Universitária, Campinas-SP, Brazil.E-mail:mario@fea.unicamp.br

a Department of Food and Nutrition, University of Campinas, Campinas, São Paulo 13083-862, Brazil

b Brazilian Agricultural Research Corporation, Embrapa Tropical Semi-arid, Petrolina, Pernambuco 56302-970, Brazil

c Brazilian Agricultural Research Corporation, Embrapa Grape and Wine/Tropical Semi-arid, Petrolina, Pernambuco 56302-970, Brazil

d Department of Agri-Food Industry, Food \& Nutrition, 'Luiz de Queiroz' College of Agriculture, University of São Paulo, CEP 13418-900, Piracicaba, SP, Brazil
} 
disease. ${ }^{18}$ Castilla et al. ${ }^{19}$ found greater antioxidant capacity and high-density lipoprotein cholesterol, as well as a reduction in low-density lipoprotein (LDL) cholesterol in plasma of healthy adults and adults in hemodialysis subsequent to the daily ingestion of concentrated grape juice ( $100 \mathrm{~mL}$ for 14 days). In another study, supplementation with $480 \mathrm{~mL}$ of grape juice for 8 weeks showed protection against DNA damage in healthy adults of both genders. ${ }^{20}$ All of these facts indicate that grape juice has the potential to maintain health and collaborate in the control of disease.

Grape juice is a representative product of grape processing and there is a constant need for improvement of its sensory quality and nutritional properties. Brazilian grape juice is mainly produced using Isabella cultivar, owing to its large production and the foxy aroma/flavor characteristic of Vitis labrusca cultivars. However, the color of Isabella grape juice generally needs to be improved, as the color is the first sensory attribute evaluated by consumers. The grape BRS-Cora, developed by the Brazilian Agricultural Research Agency (EMBRAPA) via the cross between 'Muscat Belly $A^{\prime}$ and ' $H$. 65.9.14', ${ }^{21}$ is frequently used to produce grape juice in Brazil, especially to produce blends with Isabella cultivar to improve the final color of the juice. Furthermore, the polyphenol content and antioxidant properties of BRS-Cora are equally important.

A quick search of the literature demonstrates that only a few reports have addressed the phenolic profile and antioxidant potential of Isabella cultivar grape juice, and most of them are of local relevance, which also applies to BRS-Cora grape juice. Brazil is very important as a grape juice producer, which makes the present work of international relevance for both researchers and industry. Thus the aim of the present work was to evaluate the phenolic profile and antioxidant properties of grape juices produced with Isabella and BRS-Cora cultivars.

\section{MATERIAL AND METHODS}

\section{Sample and juice preparation}

Grapes (cv. Isabella and BRS-Cora) were harvested and provided by Embrapa Tropical Semi-arid, Petrolina, Pernambuco State, Brazil (latitude $9^{\circ} 8^{\prime}$ 8.9' S, longitude $40^{\circ} 18^{\prime} 33.6^{\prime \prime} \mathrm{W}$, altitude $373 \mathrm{~m}$ ).

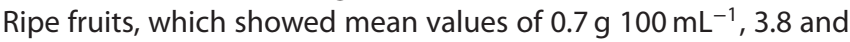
$23^{\circ}$ Brix for total acidity, $\mathrm{pH}$ and sugar level, respectively, were harvested and stored at $10^{\circ} \mathrm{C}$ for $12 \mathrm{~h}$ after processing. First, the grapes were sanitized with hypochlorite solution $\left(100 \mathrm{mg} \mathrm{L}^{-1}\right)$ for $15 \mathrm{~min}$ and rinsed with water. Fruits were then processed by the steam extraction method for $60 \mathrm{~min}$ at $75-85^{\circ} \mathrm{C}$. Sterilized glass bottles were used for juice storage $\left(16^{\circ} \mathrm{C}\right)$ until analysis, within 30 days of juice bottling.

\section{Total polyphenol content (TPC)}

TPC was determined using the Folin-Ciocalteu method, ${ }^{22}$ with slight modifications. The extracts, distilled water and Folin-Ciocalteau's reagent were added to vials and mixed thoroughly. After $3 \mathrm{~min}, 2 \mathrm{~mol} \mathrm{~L}^{-1}$ sodium carbonate solution were added and the mixture was kept in the dark at room temperature for $2 \mathrm{~h}$. The absorbance was read at $725 \mathrm{~nm}$ using a spectrophotometer (Synergy HT, Biotek, Winooski, VT, USA). Gallic acid was used to prepare a standard curve and the results were expressed as gallic acid equivalents (mg GAE $100 \mathrm{~mL}^{-1}$ of juice).

\section{Total anthocyanins}

Total anthocyanins were measured according to Wrolstad, ${ }^{23}$ with some modifications, as described by Abe et al. ${ }^{24}$ Appropriate dilutions from the samples were carried out using $0.025 \mathrm{~mol} \mathrm{~L}^{-1}$ potassium chloride buffer ( $\mathrm{pH}$ 1.0). The absorbance was read at 510 and $700 \mathrm{~nm}$ using a microplate reader (Synergy HT). A second dilution was made for each sample using $0.4 \mathrm{~mol} \mathrm{~L}^{-1}$ sodium acetate buffer (pH 4.5) and the absorbance was read at the same wavelengths. The calculations were done as shown in the equation below:

$A=\left[\left(A_{510 \mathrm{~nm}}-A_{700 \mathrm{~nm}}\right) \mathrm{pH}=1.0\right]-\left[\left(A_{510 \mathrm{~nm}}-A_{700 \mathrm{~nm}}\right) \mathrm{pH}=4.5\right]$

The results were expressed as mg cyanidin 3-glucoside $100 \mathrm{~mL}^{-1}$. The final results were calculated as follows:

$$
C\left(\mathrm{mg} 100 \mathrm{~mL}^{-1}\right)=\text { A.MW.DF. } 100 \div \xi .1
$$

where $\xi=$ molar absorptivity $\left(26900 \mathrm{~mol} \mathrm{~L}^{-1}\right), 1=$ path length (cm), MW = molecular weight of cyanidin 3-glucoside and $\mathrm{DF}=$ dilution factor.

\section{Analysis by high-performance liquid chromatography (HPLC)} Phenolic compounds were identified and quantified by HPLC technique using a Waters Alliance e2695 HPLC system equipped with a photodiode array detector (DAD) and fluorescence detectors (FLD). Separations were performed on a C18 column $(150 \times 4.6 \mathrm{~mm}, 3 \mu \mathrm{m}$ Gemini NX, Phenomenex, Torrance, CA, USA); preceding the analytical column a C18 guard column was used $\left(4.0 \times 3.0 \mathrm{~mm}\right.$, Gemini NX) at $40^{\circ} \mathrm{C}$. The mobile phase consisted of a $25 \mathrm{mmol} \mathrm{L}^{-1}$ solution of potassium dihydrogen phosphate in ultrapure water (PURELAB Option Q, Elga Systems, Woodridge, IL, USA) with $\mathrm{pH}$ adjusted to 2.05 using phosphoric acid (Fluka, Switzerland) as solvent A, methanol (HPLC grade, JT Baker, Phillipsburg, NJ, USA), as solvent B and acetonitrile (HPLC grade, JT Baker) as solvent $C$. The elution gradient used was as follows: $0 \mathrm{~min} 100 \% \mathrm{~A} ; 18 \mathrm{~min} 87.5 \% \mathrm{~A}, 2.5 \% \mathrm{~B}, 10.0 \% \mathrm{C} ; 30 \mathrm{~min}$ $83.5 \% \mathrm{~A}, 3.2 \% \mathrm{~B}, 13.3 \% \mathrm{C} ; 36 \mathrm{~min} 75.0 \% \mathrm{~A}, 5.0 \% \mathrm{~B}, 20.0 \% \mathrm{C}$; $48.5 \min 65.0 \%$ A, 8.3\% B, 26.7\% C; $50 \min 65.0 \%$ A, 8.3\% B, 26.7\% $\mathrm{C}$ and $65 \mathrm{~min} 100 \% \mathrm{~A}$. The flow rate and injection volume were $0.6 \mathrm{~mL} \mathrm{~min}^{-1}$ and $10 \mu \mathrm{L}$, respectively. The juices were previously filtered through a $0.45 \mu \mathrm{m}$ membrane before injection into the HPLC system. Phenolic compounds were identified by comparing their relative retention times (RT) and UV spectral data with those of identical standards at $520 \mathrm{~nm}$ (pelargonidin 3-O-glucoside, cyanidin 3-O-glucoside, delphinidin 3-O-glucoside, peonidin 3-O-glucoside, malvidin 3-O-glucoside), $220 \mathrm{~nm}$ (gallic acid, procyanidin B1, (-)-epicatechin gallate and (-)-epigalocatechin gallate), $320 \mathrm{~nm}$ (chlorogenic acid, caffeic acid, $p$-coumaric acid and ferrulic acid) and $360 \mathrm{~nm}$ (isorhamnetin-3-O-glucoside and rutin). The fluorescence detector was used for the detection of the vanillic acid, procyanidin B2 and A2, (-)-epicatechin, (+)-catechin and syringic acid at $280 \mathrm{~nm}$ of the excitation and $360 \mathrm{~nm}$ of the emission. The standards caffeic, vanillic, ferrulic and gallic acids were purchased from Chem Service (West Chester, PA, USA). Chlorogenic, syringic and $p$-coumaric acids were purchased from Sigma (UK). Pelargonidin 3-O-glucoside, cyanidin 3-O-glucoside, delphinidin 3-O-glucoside, peonidin 3-O-glucoside, malvidin 3-O-glucoside, procyanidin B1, procyanidin B2, procyanidin A2, epicatechin, catechin, epicatechin gallate, epigalocatechin gallate, rutin and isorhamnetin-3-O-glucoside were obtained from Extrasynthese (Genay, France). Calibration curves were prepared 
for these 21 standard phenolic compounds using the same chromatographic conditions. Table 1 shows the concentration range of each standard used for the calibration curves, standards purity (SP), equations of the calibration curves, coefficients of determination $\left(R^{2}\right)$, detection limits (LD), quantification limits (LQ) and assay repeatability through coefficient of variation (CV). Data collection and analysis were carried out using Empore ${ }^{\mathrm{TM}} 2$ software (Milford, CT, USA).

\section{Antioxidant activity \\ DPPH radical scavenging activity}

The antioxidant activity was determined using the DPPH (1,1-diphenyl-2-picrylhydrazil) assay according to Brand-Williams et al., ${ }^{25}$ with some modifications. Briefly, $61 \mu \mathrm{mol} \mathrm{L}{ }^{-1}$ DPPH ethanol solution were added to the extracts, followed by shaking and incubation for $30 \mathrm{~min}$ in the dark. The absorbance was read at $515 \mathrm{~nm}$ using a Synergy HT spectrometer. The results were expressed as $\mu \mathrm{mol}$ Trolox equivalents (TE) $100 \mathrm{~mL}^{-1}$ of juice.

\section{Hydrophilic oxygen radical absorbance capacity (ORAC) assay}

The ORAC assay was determined according to Dávalos et al. ${ }^{26}$ The extracts were prepared in phosphate buffer (PB) $\left(75 \mathrm{mmol} \mathrm{L}^{-1}\right.$, $\mathrm{pH}$ 7.4). The peroxyl radical was generated using $2,2^{\prime}$-azobis (2-amidinopropane) dihydrochloride solution (AAPH) and fluorescein was used as the substrate. The reaction mixture consisted of extracts, $0.0014 \mathrm{mmol} \mathrm{L}^{-1}$ fluorescein, and $0.4 \mathrm{~mol} \mathrm{~L}^{-1} \mathrm{AAPH}$. The reaction was carried out in a plate reader (Synergy $\mathrm{HT}$ ) with filters of emission at $520 \mathrm{~nm}$ and excitation at $485 \mathrm{~nm}$. The incubation was conducted at $37^{\circ} \mathrm{C}$. The fluorescence was recorded every minute for $80 \mathrm{~min}$. The Trolox standard was used to prepare a standard curve and the results were expressed as $\mu \mathrm{mol}$ TE $100 \mathrm{~mL}^{-1}$ juice.

\section{Ferric reducing antioxidant power (FRAP) assay}

The FRAP assay was carried out according to Rufino et al., ${ }^{27}$ with slight modifications. In the dark, FRAP reagent was prepared with $300 \mathrm{mmol} \mathrm{L}^{-1}$ acetate buffer $(\mathrm{pH} 3.6), 10 \mathrm{mmol} \mathrm{L}^{-1}$ 2,4,6-tris(2-pyridyl)-s-triazine (TPTZ) in a $40 \mathrm{mmol} \mathrm{L}^{-1} \mathrm{HCl}$ solution and $20 \mathrm{mmol} \mathrm{L}^{-1} \mathrm{FeCl}_{3}$. Samples or standard solutions, ultrapure water and FRAP reagent were mixed and allowed to react in a water bath for $30 \mathrm{~min}$ at $37^{\circ} \mathrm{C}$. After cooling to room temperature, the absorbance of the samples and standards was read at $595 \mathrm{~nm}$. Results were expressed in $\mu \mathrm{mol}$ TE $100 \mathrm{~mL}^{-1}$ juice.

\section{Statistical analysis}

All analyses were carried out in triplicate and data were expressed as the mean value \pm standard error (SEM). The statistical analyses were carried out using GraphPad Prism 5.0 software (GraphPad Software, Inc., La Jolla, CA, USA). The significance of the data was determined using Student's $t$-test at $P<0.05$.

\section{RESULTS AND DISCUSSION \\ Total phenolic and anthocyanin content}

Fruits and plant-derived beverages such as fruit juices are dietary sources of polyphenols. Polyphenols have received increasing interest from consumers and the food industry because of the direct association between their consumption and the prevention of several diseases. Plant polyphenols have antioxidant properties and therefore an important role against radical oxygen species
(ROS). ${ }^{28,29}$ Enhancements in the cognitive function of adults after the ingestion of 6-9 $\mathrm{mL}$ grape juice $\mathrm{kg}^{-1}$ body weight for 12 weeks have also been reported. ${ }^{30}$ Other authors have found positive effects in the lipid profile, ${ }^{19}$ antioxidant status ${ }^{31}$ and antimutagenic activity ${ }^{20}$ after grape juice consumption, which supports the potential health benefits of this product.

In the present study, BRS-Cora grape juice showed higher bioactive substance concentrations than that found in grape juice prepared with the Isabella cultivar. BRS-Cora grape juice showed three times higher TPC $\left(221.6 \pm 1.83 \mathrm{mg} \mathrm{GAE} 100 \mathrm{~mL}^{-1}\right)$ than Isabella $\left(74.86 \pm 4.25 \mathrm{mg} \mathrm{GAE} 100 \mathrm{~mL}^{-1}\right.$ ) (Fig. 1a). Furthermore, BRS-Cora grape juice also had an anthocyanin content that was five times higher $\left(73.88 \pm 1.30 \mathrm{mg}\right.$ cyanidin-3-glucoside $\left.100 \mathrm{~mL}^{-1}\right)$ than Isabella grape juice $(15.40 \pm 0.20 \mathrm{mg}$ cyanidin-3-glucoside $100 \mathrm{~mL}^{-1}$ ) (Fig. 1b).

The results presented here are in good agreement with those reported for Campbell Early grape juice, for which TPC was found at a concentration of $308.2 \pm 11.0 \mathrm{mg} \mathrm{GAE} 100 \mathrm{~mL}^{-1}$ and content of $496.6 \pm 15.0 \mathrm{mg}$ expressed as malvidin-3-glucoside $100 \mathrm{~mL}^{-1}$ for total anthocyanins ${ }^{32}$. Minor differences are expected due to different cultivars, climate conditions, soil quality and losses during the juice-making process. ${ }^{13-15,33,34}$ Compared to other fruit juices, the analyzed grape juices are rich sources of polyphenol compounds. Pala and Toklucu ${ }^{35}$ observed a lower anthocyanin content in pomegranate juice $(42.6 \pm 1.37 \mathrm{mg}$ cyanidin 3 -glucoside $100 \mathrm{~mL}^{-1}$ ).

\section{HPLC analysis}

Phenolic compounds are widely distributed in plants, and grapes are well recognized as good sources of polyphenols from several classes. In the present study, 21 phenolic compounds were positively identified and quantified by HPLC (Table 2).

Anthocyanins represent a significant portion of the total polyphenols in grapes. $^{32}$ These compounds are among the most important groups of water-soluble pigments, concentrated mainly in the fruit skin, being responsible for the purplish color of the grape and the antioxidant properties. ${ }^{36}$ Isabella grape juice showed a higher content of four monoglycosylated anthocyanins (Table 2), but delphinidin 3-O-glucoside was eight times more concentrated in BRS-Cora. Some works have shown prevalence of anthocyanins 3,5-diglucoside in non-vinifera grape cultivars and their hybrids. ${ }^{37-39}$ Diglucosidic anthocyanins were not investigated in the present study; however, as can be noted in Table 2, the phenolic total content (anthocyanins + phenolic acids + flavonoids/proanthocyanidins) was higher in BRS-Cora grape juice, supporting the TPC data. These compounds may be able to avoid certain diseases, thus providing a better life quality. ${ }^{40}$

The major phenolic compounds of BRS-Cora grape juice were delphinidin 3-O-glucoside, proanthocyanidin B1, ferulic acid and caffeic acid. Proanthocyanidin B1, malvidin 3-O-glucoside, syringic acid and catechin were the major ones in Isabella grape juice. In general, the concentration of individual phenolic compounds was different $(P \leq 0.05)$ between the samples. BRS-Cora grape juice rendered a higher concentration of most of the phenolics quantified, which is in agreement with the trend observed in TPC and anthocyanin analyses.

Among all the phenolic compounds identified, only isorhamnetin and malvidin 3-O-glucoside were not found in BRS-Cora grape juices, and $p$-coumaric acid and epicatechin gallate were not found in Isabella grape juices. trans-Resveratrol, kaempferol-3-O-glucoside, myricetin and quercetin were not identified in either juice. 
Table 1. Concentration range $\left(\mathrm{CR}, \mathrm{mg} \mathrm{L}^{-1}\right)$ of the standards used to prepare the calibration curves, standards purity (SP, \%), equations of the calibration curves, coefficients of determination $\left(R^{2}\right)$, detection limits $\left(\mathrm{LD}, \mathrm{mg} \mathrm{L}^{-1}\right)$, quantification limits $\left(\mathrm{LQ}, \mathrm{mg} \mathrm{L}^{-1}\right)$ and assay repeatability through coefficient of variation (CV, \%)

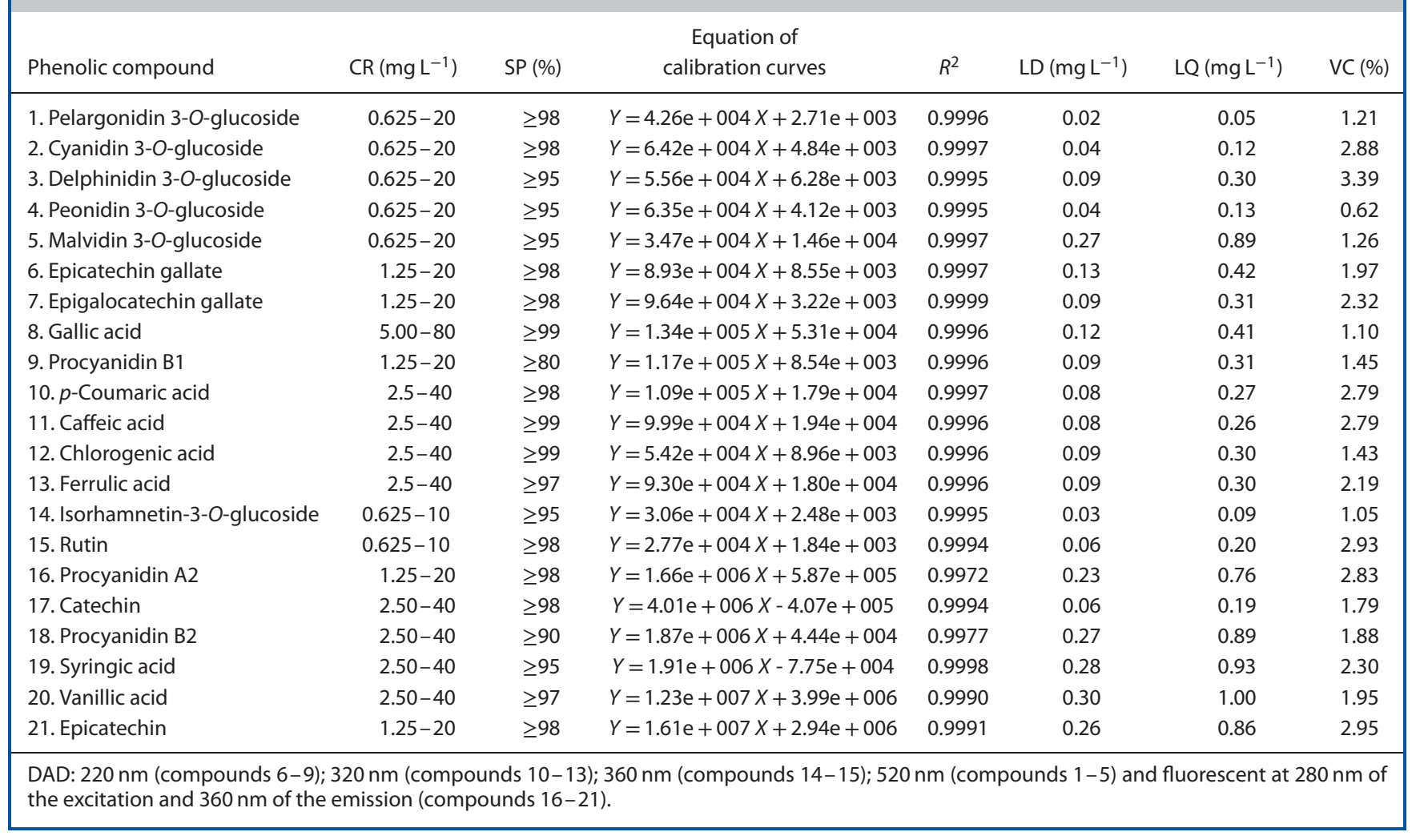
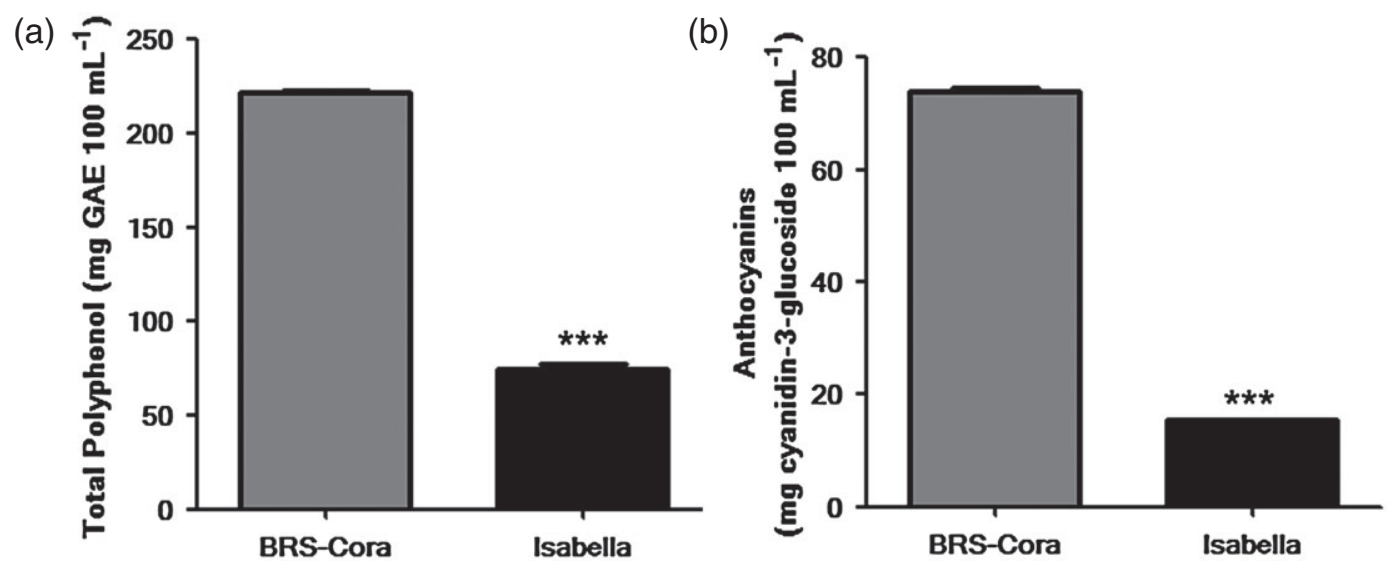

Figure 1. Total polyphenols (a) and anthocyanin contents (b). GAE, gallic acid equivalent. Data are expressed as means \pm SEM. Coefficient of variation (CV) for total polyphenols and total anthocyanins were $3.2 \%$ and $1.6 \%$, respectively. Asterisks Indicate a significant difference between BRS-Cora and Isabella grape juice, as analyzed by Student's $t$-test $\left({ }^{* *} P \leq 0.001\right)$.

Supporting the findings of the present study, Sensoy ${ }^{41}$ also found caffeic acid and syringic acids as the major compounds in varieties of red grapes. However, grape juices prepared with Sauvignon Blanc cultivar showed higher catechin and lower caffeic acid concentrations than those found in the present study, within the range of $4.5-7.7$ and $0.41-3.7 \mathrm{mg} \mathrm{L}^{-1}$, respectively. ${ }^{42}$ Such differences may be correlated with the different grape cultivars compared as the present study, which used red grapes, and these authors used Sauvignon Blanc, which is a white grape. However, Ghafoor et al. ${ }^{32}$ did not find caffeic acid in grape juice prepared with Campbell Early grape. According to Sun et al., ${ }^{43}$ ellagic acid is the major compound observed in different polyphenol profiles of some grape varieties (Fernão Pires, Castelão, Vital, Vinhão, Espadeiro, Azal Tinto). The present study is in accordance with the literature in relation to the variation in polyphenol composition among different grape cultivars. BRS-Cora was developed by Embrapa, Brazil, with the objective of creating new varieties for grape juice as an alternative to emerging Brazilian regions for grape production, with high productivity, sugar content, color intensity and good sensory quality of grape juice, as well as the Vitis labrusca cultivars Isabella and Concord. ${ }^{44}$ Therefore, it was expected that BRS Cora grape juice had a higher anthocyanins 


\begin{tabular}{|c|c|c|}
\hline & BRS-CORA & Isabella \\
\hline \multicolumn{3}{|l|}{ Anthocyanins } \\
\hline Pelargonidin 3-O-glucoside & $0.33 \pm 0.03^{b}$ & $3.28 \pm 0.03^{\mathrm{a}}$ \\
\hline Cyanidin 3-O-glucoside & $2.77 \pm 0.03^{b}$ & $3.27 \pm 0.03^{\mathrm{a}}$ \\
\hline Delphinidin 3-O-glucoside & $23.3 \pm 0.10^{\mathrm{a}}$ & $2.80 \pm 0.50^{\mathrm{b}}$ \\
\hline Peonidin 3-O-glucoside & $0.55 \pm 0.00^{b}$ & $6.39 \pm 0.05^{\mathrm{a}}$ \\
\hline Malvidin 3-O-glucoside & ND & $23.2 \pm 0.18$ \\
\hline$\Sigma$ Anthocyanins & $26.98 \pm 0.09^{b}$ & $38.85 \pm 0.15^{\mathrm{a}}$ \\
\hline \multicolumn{3}{|l|}{ Phenolic acids } \\
\hline Gallic acid & $3.52 \pm 0.03^{\mathrm{a}}$ & $1.75 \pm 0.00^{\mathrm{b}}$ \\
\hline Caffeic acid & $7.42 \pm 0.29^{\mathrm{a}}$ & $1.50 \pm 0.00^{\mathrm{b}}$ \\
\hline Syringic acid & $6.02 \pm 0.13^{b}$ & $11.38 \pm 0.40^{\mathrm{a}}$ \\
\hline Vanillic acid & $0.58 \pm 0.03^{\mathrm{a}}$ & $0.25 \pm 0.00^{\mathrm{b}}$ \\
\hline Ferulic acid & $19.20 \pm 1.13^{\mathrm{a}}$ & $0.62 \pm 0.03^{b}$ \\
\hline Chlorogenic acid & $1.85 \pm 0.45$ & $1.85 \pm 0.00$ \\
\hline$p$-coumaric acid & $1.32 \pm 0.03$ & ND \\
\hline$\Sigma$ Phenolic acids & $39.90 \pm 0.51^{\mathrm{a}}$ & $17.35 \pm 0.16^{b}$ \\
\hline \multicolumn{3}{|l|}{ Flavonoids/proanthocyanidins } \\
\hline Isorhamnetin 3-O-glucoside & ND & $0.55 \pm 0.00$ \\
\hline Catechin & $2.57 \pm 0.03^{b}$ & $2.68 \pm 0.03^{a}$ \\
\hline Epicatechin & $1.83 \pm 0.03^{\mathrm{a}}$ & $0.20 \pm 0.00^{\mathrm{b}}$ \\
\hline Epicatechin gallate & $1.95 \pm 0.09$ & ND \\
\hline Epigallocatechin gallate & $4.65 \pm 0.07^{\mathrm{a}}$ & $0.48 \pm 0.02^{b}$ \\
\hline Proanthocyanidin A2 & $1.15 \pm 0.05^{b}$ & $1.35 \pm 0.03^{\mathrm{a}}$ \\
\hline Proanthocyanidin B1 & $20.78 \pm 0.69^{b}$ & $32.57 \pm 0.20^{\mathrm{a}}$ \\
\hline Proanthocyanidin B2 & $3.33 \pm 0.03^{\mathrm{a}}$ & $1.92 \pm 0.39^{b}$ \\
\hline Rutin & $5.42 \pm 0.03^{\mathrm{a}}$ & $1.63 \pm 0.03^{b}$ \\
\hline $\begin{array}{l}\sum \\
\text { Flavonoids/proanthocyanidir }\end{array}$ & $41.68 \pm 0.14$ & $41.38 \pm 0.08$ \\
\hline $\begin{array}{l}\Sigma \text { Phenolic compounds } \\
\text { (anthocyanins + phenolic } \\
\text { acids + flavonoids/ } \\
\text { proanthocyanidins) }\end{array}$ & $108.86 \pm 0.37^{a}$ & $97.58 \pm 0.17^{b}$ \\
\hline \multicolumn{3}{|c|}{$\begin{array}{l}\text { Data are expressed as means } \pm \text { SEM. Values followed by a different } \\
\text { superscript in the same row are significantly different }(P \leq 0.05) \text { from } \\
\text { Cora grape according to the Student's } t \text {-test. ND, not detected. }\end{array}$} \\
\hline
\end{tabular}

content, as shown in Fig. 1. Additionally, Table 2 shows that BRS Cora also presents a higher content of other phenolic compounds compared to Isabella grape juice, suggesting that the presence of this cultivar in the juice can contribute to improve benefits of grape juice consumption for human health. Furthermore, different techniques used for juice production may generate different polyphenol contents in the final product, but it is not the case for the juices evaluated.

As previously mentioned, phenolic compounds have shown health benefits against LDL oxidation as well as in the reduction of DNA damage and free radical level in blood plasma. ${ }^{45-47}$ Furthermore, proanthocyanidins, which are among the major phenolic compounds of BRS Cora and Isabella grape juice, have been associated with the prevention of urinary tract infections. ${ }^{48}$ Grape seed extracts containing catechin, epicatechin and proanthocyanidins also demonstrated positive effects on prevention of Alzheimer's disease in animal models. ${ }^{49}$ Sato et al. ${ }^{50}$ demonstrated that caffeic acid has strong antioxidant potential in vitro and in vivo. Finally, syringic acid has shown a hepato-protective effect in mice subjected to induced liver injury. ${ }^{51}$ Thus phenolic compounds

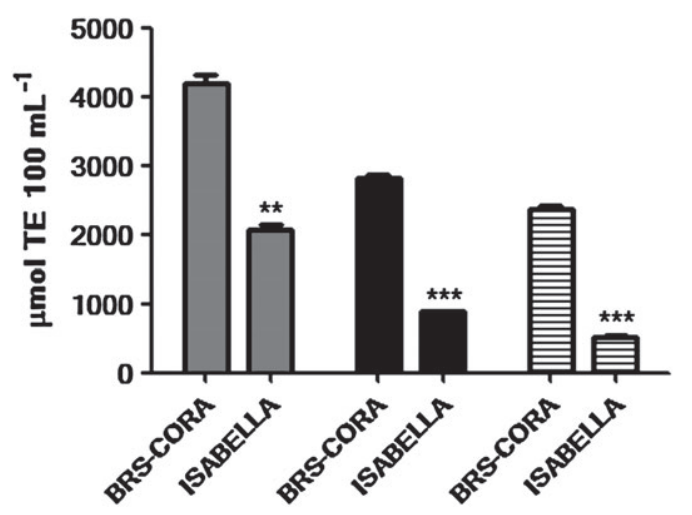

Figure 2. Antioxidant potential of grape juices as evaluated by ORAC, FRAP and DPPH methods ( $\mu \mathrm{mol}$ Trolox equivalent (TE) $100 \mathrm{~mL}^{-1}$ juice). Data are expressed as means \pm SEM. Coefficients of variation (CV) for ORAC, FRAP and DPPH were $6.3 \%, 2.9 \%$ and $4.9 \%$, respectively. Asterisks indicate a significant difference between BRS-Cora and Isabella grape juice as analyzed by Student's $t$-test $\left({ }^{* *} P \leq 0.01 ;{ }^{* *} P \leq 0.001\right)$.

Table 3. Pearson's correlation coefficients $(r)$ between bioactive compounds and antioxidant capacity of BRS-Cora and Isabella grape juices

\begin{tabular}{|lcccccccc|} 
& \multicolumn{3}{c}{ Polyphenols } & & \multicolumn{3}{c}{ Anthocyanins } \\
\cline { 2 - 4 } \cline { 7 - 8 } Parameter & ORAC & FRAP & DPPH & & ORAC & FRAP & DPPH \\
\hline$r$ & 0.9872 & 0.9966 & 0.9989 & & 0.9916 & 0.9963 & 0.9992 \\
$P$ & 0.0002 & $<0.0001$ & $<0.0001$ & 0.0001 & $<0.0001$ & $<0.0001$ \\
$r^{2}$ & 0.9745 & 0.9931 & 0.9978 & 0.9833 & 0.9925 & 0.9983 \\
\hline \multicolumn{2}{r}{$r$, correlation coefficient; $r^{2}$, determination coefficient. } \\
\hline
\end{tabular}

identified in BRS-Cora and Isabella will likely provide health benefits for consumers.

\section{Antioxidant activity}

Oxidative stress may rise in the cell, affecting the integrity of biomolecules and increasing the risk of oxidative-related diseases. Polyphenols found in berry fruits possess antioxidant properties, ${ }^{52}$ which may be beneficial against oxidative stress. The in vitro evaluation of antioxidant capacity is helpful in anticipating the potential of food products to prevent oxidative damage in vivo. It is also important for consumers, helping them to make decisions and choose foods to achieve a better diet. Data about the bioavailability of polyphenols are still scarce due to the complexity of this kind of investigation. However, some studies showing the presence of these compounds in blood and tissues and, most recently, metabolomics databases with information on metabolites are becoming available, which may contribute to establishing relationships among different sources of polyphenols, their intake and human health improvement..$^{53-55}$

In the present study, the antioxidant properties of grape juices were evaluated by oxygen radical absorbance capacity (ORAC), ferric reducing antioxidant power (FRAP) and DPPH radical scavenging activity. ORAC relies on chain-breaking antioxidant capacity against peroxyl radicals, ${ }^{56}$ FRAP involves the reduction of ferric to ferrous ions via electron transfer, ${ }^{27}$ and DPPH involves hydrogen donation. ${ }^{25}$ Peroxyl radicals are reactive oxygen species (ROS), thus being detrimental to health due to the oxidative processes in which they are active. Because of their relatively long half-life, 
their effect may occur at both a cellular level and in biological fluids. Ferric ions are also detrimental to biological systems, as they catalyze the oxidation of proteins and lipids. Finally, DPPH is a synthetic radical that has been widely applied to in vitro antioxidant evaluations as a preliminary screen of the antioxidant properties of several food products. ${ }^{57}$

The results of the antioxidant evaluation are summarized in Fig. 2. The antioxidant activity of BRS-Cora grape juice was 2.3-, 3- and 4.5-fold higher than Isabella grape juice, as evaluated by ORAC, FRAP and DPPH, respectively. These results are supported by the higher TPC and anthocyanins found in BRS-Cora grape juice (Fig. 1). Furthermore, a strong positive correlation was found in TPC or anthocyanins and the remaining antioxidant assays (ORAC, FRAP and DPPH) (Table 3).

Antioxidants can stop free radical chain reactions via the donation of hydrogen from their phenolic hydroxyl groups or electrons, thus generating stable end-products that do not take part in further oxidation processes. ${ }^{58}$ Therefore, in general, the antioxidant activity of food products reflects their polyphenol content, as demonstrated in the present study. Both grape juices had antioxidant properties in neutralizing peroxyl radicals and in reducing ferric ions, as evaluated by ORAC and FRAP, respectively. Both methods possess biological relevance. ${ }^{59,60}$ Thus grape juice consumption will likely have health benefits. Finally, BRS-Cora, which is a relatively new cultivar (it was launched in 2004), ${ }^{44}$ showed the highest antioxidant properties in all antioxidant assays when compared to Isabella. However, BRS-Cora is still underused. Thus the grape juice industry should consider the use of BRS-Cora to produce grape juice or use them to produce blends with Isabella, improving not only the color of the juice but also their health benefits.

\section{CONCLUSION}

BRS-Cora grape juice showed higher TPC, anthocyanin content and antioxidant potential than Isabella grape juice. Twenty-one phenolic compounds were positively identified and quantified using HPLC-DAD-FLD. Little difference was found in the identity of phenolics between the cultivars; however, their quantification demonstrated significant differences in the grape juices made with BRS-Cora and Isabella grapes. BRS-Cora grape juice had up to two and ten times higher concentrations of gallic acid and epigallocatechin gallate, respectively, than that found in Isabella grape juice. Furthermore, epicatechin gallate was identified and quantified only in BRS-Cora. Gallic acid and polyphenols bearing galloyl groups probably had an influence on the higher antioxidant potential of BRS-Cora grape juice. In this way, the use of BRS-Cora is a good alternative to produce grape juice or in blends with different cultivars. The new cultivar BRS-Cora has been used to improve the color of Brazilian grape juice; however, as new information, the present work demonstrated that the use of BRS-Cora may also offer improvements in the phenolic profile and antioxidant potential of the product, being a potential functional food.

\section{ACKNOWLEDGEMENTS}

The authors wish to thank FAPESP (grants 2010/16752-3, 2012/17683-0), CAPES and CNPq (300533/2013-6) for their financial support. The authors declare that they do not have any conflicts of interest to disclose.

\section{REFERENCES}

1 Kar P, Laight D, Rooprai HK, Shaw KM and Cummings M, Effects of grape seed extract in Type 2 diabetic subjects at high cardiovascular risk: a double blind randomized placebo controlled trial examining metabolic markers, vascular tone, inflammation, oxidative stress and insulin sensitivity. Diabetic Med 26:526-531 (2009).

2 Arimoto-Kobayashi S, Zhang X, Yuhara Y, Kamiya T, Negishi T and Okamoto G, Chemopreventive effects of the juice of vitis coignetiae Pulliat on two-stage mouse skin carcinogenesis. Nutr Cancer 65:440-450 (2013).

3 Vislocky LM and Fernandez ML, Biomedical effects of grape products. Nutr Rev 68:656-670 (2010).

4 Bravo L, Polyphenols: chemistry, dietary sources, metabolism, and nutritional significance. Nutr Rev 56:317-333 (1998).

5 Jacob JK, Hakimuddin F, Paliyath G and Fisher H, Antioxidant and antiproliferative activity of polyphenols in novel high-polyphenol grape lines. Food Res Int 41:419-428 (2008).

6 Joseph JA, Shukitt-Hale B and Willis LM, Grape juice, berries, and walnuts affect brain aging and behavior. J Nutr 139:1813s-1817s (2009).

7 Middleton E, Kandaswami C and Theoharides TC, The effects of plant flavonoids on mammalian cells: implications for inflammation, heart disease, and cancer. Pharmacol Rev 52:673-751 (2000).

8 Monagas M, Gómez-Cordovés C, Bartolomé B, Laureano O and Ricardo-Da-Silva JM, Monomeric, oligomeric, and polymeric flavan-3-ol composition of wines and grapes from Vitis vinifera L. Cv. Graciano, Tempranillo, and Cabernet Sauvignon. J Agric Food Chem 51:6475-6481 (2003).

9 Sandhu AK, Gray DJ, Lu J and Gu L, Effects of exogenous abscisic acid on antioxidant capacities, anthocyanins, and flavonol contents of muscadine grape (Vitis rotundifolia) skins. Food Chem 126:982-988 (2011).

10 De Nisco M, Manfra M, Bolognese A, Sofo A, Scopa A, Tenore GC et al., Nutraceutical properties and polyphenolic profile of berry skin and wine of Vitis vinifera L. (cv. Aglianico). Food Chem 140:623-629 (2013).

11 Machado MM, Dos Santos Montagner GFF, Boligon A, Athayde ML, Da Rocha MIUM, Lera JPB et al., Determination of polyphenol contents and antioxidant capacity of no-alcoholic red grape products (vitis labrusca) from conventional and organic crops. Quimica Nova 34:798-803 (2011).

12 Treutter D, Managing phenol contents in crop plants by phytochemical farming and breeding: visions and constraints. Int $\mathrm{J} \mathrm{Mol} \mathrm{Sci}$ 11:807-857 (2010).

13 Cazarin CBB, Correa LC, Da Silva JK, Batista AG, Furlan CP, Biasoto ACT et al., Tropical Isabella grape juices: bioactive compounds and antioxidant power depends on harvest season J Food Sci Eng 3:64-70 (2013).

14 Ky I, Lorrain B, Kolbas N, Crozier A and Teissedre PL, Wine by-products: phenolic characterization and antioxidant activity evaluation of grapes and grape pomaces from six different french grape varieties. Molecules 19:482-506 (2014).

$15 \mathrm{Ky}$ l and Teissedre $\mathrm{PL}$, Characterisation of mediterranean grape pomace seed and skin extracts: polyphenolic content and antioxidant activity. Molecules 20:2190-2207 (2015).

16 Sabir A, Comparison of green grafting techniques for success and vegetative development of grafted grape cultivars (Vitis spp.). Int J Agric Biol 13:628-630 (2011).

17 Verma SK, Singh SK, Krishna H and Patel VB, Comparative performance of different grafting techniques in grape cv. Pusa Urvashi. Indian J Hortic 69:13-19 (2012).

18 Stein JH, Keevil JG, Wiebe DA, Aeschlimann S and Folts JD, Purple grape juice improves endothelial function and reduces the susceptibility of LDL cholesterol to oxidation in patients with coronary artery disease. Circulation 100:1050-1055 (1999).

19 Castilla P, Echarri R, Davalos A, Cerrato F, Ortega H, Teruel JL et al., Concentrated red grape juice exerts antioxidant, hypolipidemic, and antiinflammatory effects in both hemodialysis patients and healthy subjects. Am J Clin Nutr 84:252-262 (2006).

20 Park YK, Park E, Kim JS and Kang MH, Daily grape juice consumption reduces oxidative DNA damage and plasma free radical levels in healthy Koreans. Mutat Res - Fund Mol M 529:77-86 (2003).

21 Camargo UA, Maia JDG and Ritschel PS, Embrapa Uva e Vinho - novas cultivares brasileiras de uva. Empresa Brasileira de Pesquisa Agropecuária (Embrapa), Bento Gonçalves, Brazil (2010). 
22 Swain T and Hillis WE, The phenolic constituents of Prunus domestica. I. The quantitative analysis of phenolic constituents. J Sci Food Agric 10:63-68 (1959).

23 Wrolstad RE, Color and Pigment Analyses in Fruit Products. Oregon Agricultural Experimental Station, Corvallis, OR (1993).

24 Abe LT, Mota RVd, Lajolo FM and Genovese MI, Compostos fenólicos e capacidade antioxidante de cultivares de uvas Vitis labrusca L. e Vitis vinifera L. Cienc Tecnol Aliment 27:394-400 (2007).

25 Brand-Williams W, Cuvelier ME and Berset C, Use of a free radical method to evaluate antioxidant activity. LWT - Food Sci Technol 28:25-30 (1995).

26 Dávalos A, Bartolomé B and Gómez-Cordovés C, Antioxidant properties of commercial grape juices and vinegars. Food Chem 93:325-330 (2005).

27 Rufino MDM, Alves RE, de Brito ES, Perez-Jimenez J, Saura-Calixto F and Mancini J, Bioactive compounds and antioxidant capacities of 18 non-traditional tropical fruits from Brazil. Food Chem 121:996-1002 (2010).

28 Scalbert A and Williamson G, Dietary intake and bioavailability of polyphenols. J Nutr 130:2073S-2085S (2000).

29 Scalbert A, Johnson IT and Saltmarsh M, Polyphenols: antioxidants and beyond. Am J Clin Nutr 81:215S-217S (2005).

30 Krikorian R, Nash TA, Shidler MD, Shukitt-Hale B and Joseph JA, Concord grape juice supplementation improves memory function in older adults with mild cognitive impairment. Br J Nutr 103:730-734 (2010).

31 Yuan LH, Meng LP, Ma WW, Xiao ZX, Zhu X, Feng JF et al., Impact of apple and grape juice consumption on the antioxidant status in healthy subjects. Int J Food Sci Nutr 62:844-850 (2011).

32 Ghafoor K, Al-Juhaimi F and Choi YH, Effects of grape (Vitis labrusca B.) peel and seed extracts on phenolics, antioxidants and anthocyanins in grape juice. Pak J Bot 43:1581 - 1586 (2011).

33 Tanrioven D and Eksi A, Phenolic compounds in pear juice from different cultivars. Food Chem 93:89-93 (2005).

34 Burin VM, Ferreira-Lima NE, Panceri CP and Bordignon-Luiz MT, Bioactive compounds and antioxidant activity of Vitis vinifera and Vitis labrusca grapes: evaluation of different extraction methods. Microchem J 114:155-163 (2014).

35 Pala ÇU and Toklucu AK, Effect of UV-C light on anthocyanin content and other quality parameters of pomegranate juice. J Food Compos Anal 24:790-795 (2011).

36 Santos TD, Cavalcante RN, Rostagno MA, Queiroga CL, Eberlin MN and Meireles MAA, Extraction of polyphenols and anthocyanins from the jambul (Syzygium cumini) fruit peels. Food Public Health 3:12-20 (2013).

37 Zhu L, Zhang YL and Lu J, Phenolic contents and compositions in skins of red wine grape cultivars among various genetic backgrounds and originations. Int J Mol Sci 13:3492-3510 (2012).

38 Wang HB, Race EJ and Shrikhande AJ, Characterization of anthocyanins in grape juices by ion trap liquid chromatography-mass spectrometry. J Agric Food Chem 51:1839-1844 (2003).

39 Rebello LPG, Lago-Vanzela ES, Barcia MT, Ramos AM, Stringheta PC, Da-Silva $\mathrm{R}$ et al., Phenolic composition of the berry parts of hybrid grape cultivar BRS Violeta (BRS Rubea $\times$ IAC 1398-21) using HPLC-DAD-ESI-MS/MS. Food Res Int 54:354-366 (2013).

40 Pojer E, Mattivi F, Johnson D and Stockley CS, The case for anthocyanin consumption to promote human health: a review. Compr Rev Food Sci Food Saf 12:483-508 (2013).

41 Sensoy RIG, Determination of phenolic substances and antioxidant activities in some grape cultivars by HPLC. J Anim Plant Sci 22:448-451 (2012).

42 Fracassetti D, Lawrence N, Tredoux AGJ, Tirelli A, Nieuwoudt HH and Du Toit WJ, Quantification of glutathione, catechin and caffeic acid in grape juice and wine by a novel ultra-performance liquid chromatography method. Food Chem 128:1136-1142 (2011).
43 Sun B, Ricardo-da-Silva JM and Spranger MI, Quantification of catechins and proanthocynidins in several portuguese grapevine varieties and red wines. Cienc Tecnica Vitinicola 16:23-34 (2001).

44 Camargo UA and Maia JDG, BRS CORA: nova cultivar de uva para suco, adaptada a climas tropicais. Comunicado Técnico - Embrapa Uva e Vinho (2004).

45 Frankel EN, Waterhouse AL and Teissedre PL, Principal phenolic phytochemicals in selected california wines and their antioxidant activity in inhibiting oxidation of human low-density lipoproteins. J Agric Food Chem 43:890-894 (1995).

46 Teissedre PL, Frankel EN, Waterhouse AL, Peleg H and German JB, Inhibition of in vitro human LDL oxidation by phenolic antioxidants from grapes and wines. J Sci Food Agric 70:55-61 (1996).

47 de Camargo AC, Regitano-d'Arce MAB, Biasoto ACT and Shahidi F, Low molecular weight phenolics of grape juice and winemaking byproducts: antioxidant activities and inhibition of oxidation of human low-density lipoprotein cholesterol and DNA strand breakage. $J$ Agric Food Chem 62:12159-12171 (2014).

48 Howell AB, Botto $H$, Combescure C, Blanc-Potard AB, Gausa L, Matsumoto $\mathrm{T}$ et al., Dosage effect on uropathogenic Escherichia coli anti-adhesion activity in urine following consumption of cranberry powder standardized for proanthocyanidin content: a multicentric randomized double blind study. BMC Infect Dis 10:94 (2010).

49 Wang J, Ho L, Zhao W, Ono K, Rosensweig C, Chen L et al., Grape-derived polyphenolics prevent Abeta oligomerization and attenuate cognitive deterioration in a mouse model of Alzheimer's disease. J Neurosci 28:6388-6392 (2008)

50 Sato Y, Itagaki S, Kurokawa T, Ogura J, Kobayashi M, Hirano T et al., In vitro and in vivo antioxidant properties of chlorogenic acid and caffeic acid. Int J Pharm 403:136-138 (2011).

51 Itoh A, Isoda K, Kondoh M, Kawase M, Watari A, Kobayashi M et al., Hepatoprotective effect of syringic acid and vanillic acid on $\mathrm{CCl}_{4}$-induced liver injury. Biol Pharm Bull 33:983-987 (2010).

52 Côté J, Caillet S, Doyon G, Dussault D, Salmieri S, Lorenzo G et al., Effects of juice processing on cranberry antioxidant properties. Food Res Int 44:2907-2914 (2011)

53 Manach C, Williamson G, Morand C, Scalbert A and Remesy C, Bioavailability and bioefficacy of polyphenols in humans. I. Review of 97 bioavailability studies. Am J Clin Nutr 81:230s -242s (2005).

54 Seeram NP, Lee R and Heber D, Bioavailability of ellagic acid in human plasma after consumption of ellagitannins from pomegranate (Punica granatum L.) juice. Clin Chim Acta 348:63-68 (2004).

55 Rodriguez-Mateos A, Vauzour D, Krueger CG, Shanmuganayagam D, Reed J, Calani L et al., Bioavailability, bioactivity and impact on health of dietary flavonoids and related compounds: an update. Arch Toxicol 88:1803-1853 (2014).

56 Davalos A, Gomez-Cordoves C and Bartolome B, Extending applicability of the oxygen radical absorbance capacity (ORAC-fluorescein) assay. J Agric Food Chem 52:48-54 (2004).

57 de Camargo AC, Vieira TMFS, Rasera GB, Caniniatti-Brazaca SG, Alencar SM and Regitano-Darce MAB, Lower solvent concentration and time for extraction of peanut skin antioxidants at optimized conditions, in Peanuts: Production, Nutritional Content and Health Implications, ed. by Cook RW. Hauppage, NY, pp. 31-50 (2014).

58 Göktürk Baydar N, Özkan G and Yaşar S, Evaluation of the antiradical and antioxidant potential of grape extracts. Food Control 18:1131-1136 (2007).

59 Benzie IFF and Strain JJ, The ferric reducing ability of plasma (FRAP) as a measure of "antioxidant power': the FRAP assay. Anal Biochem 239:70-76 (1996).

60 Prior RL, Hoang H, Gu LW, Wu XL, Bacchiocca M, Howard L et al., Assays for hydrophilic and lipophilic antioxidant capacity (oxygen radical absorbance capacity (ORAC(FL)) of plasma and other biological and food samples. J Agric Food Chem 51:3273-3279 (2003). 